\title{
Surgical techniques for maxillary bone grafting - literature review
}

\section{Técnicas cirúrgicas para a enxertia óssea dos maxilares - revisão da literatura}

Leonardo Perez Faverani ; Gabriel Ramalho-Ferreira ${ }^{1}$; Paulo Henrique dos Santos ${ }^{1}$; Eduardo Passos Rocha ${ }^{1}$; Idelmo Rangel Garcia Júnior ${ }^{1}$; Cláudio Maldonado Pastori ${ }^{1}$; Wirley Gonçalves Assunção ${ }^{1}$

\section{A}

\begin{abstract}
For oral rehabilitation with implant-supported prostheses, there are required procedures to create the bone volume needed for installation of the implants. Thus, bone grafts from intraoral or extraoral donor sites represent a very favorable opportunity. This study aimed to review the literature on the subject, seeking to discuss parameters for the indications, advantages and complications of techniques for autogenous bone grafts.
\end{abstract}

Key words: Maxilla. Transplants. Bone transplantation. Prostheses and implants. Mouth rehabilitation.

\section{INTRODUCTION}

$T^{T}$ he need for correction of small or large bone defects for implant placement and subsequent rehabilitation has become routine practice of implantology. The techniques of bone grafting and partial or total reconstruction of the maxilla and mandible and of donor areas are evaluated primarily according to the degree of bone loss, surgicalprosthetic planning and general condition of the patient. There are many discussions and controversies about the use of materials to bone grafting and reconstruction; both autologous bone and allogenic and alloplastic materials can be used. However, the best results have been reported with autogenous bone, for it has osteogenic and osteoinductive capacity, and does not trigger specific immune response, making it an ideal grafting material'.

The choice of possible donor sites for bone reconstruction depends mainly on the bone volume required and the type of defect ${ }^{2}$.

Often, the disadvantages associated with this extrabuccal approach are related to the need of a second surgical site, risks of vascular and neurological injuries and postoperative morbidity ${ }^{3}$.

The ideal reconstructive material for bone replacement should facilitate revascularization, osteogenesis and osteoinduction, not display antigenic properties, exist in abundance, without the need for donor site, and provide adequate stability and support ${ }^{4}$.

Among the materials used to replace the autogenous graft, allogenous or homogenous bone appears as a viable alternative, with high success rates in guided bone regeneration procedures, and may also be used alone or in combination with xenogenous or alloplastic bone. Additional advantages include: availability of large volumes of material, extremely low antigenic potential and safety record at orthodontists 5 .

The allogenous grafts present with osteoconductive characteristics, provide structure for cell migration, and osteoinductive ones, by having a family of proteins called bone morphogenetic proteins, preserved even after freezing. These proteins are responsible for chemotaxis of mesenchymal stem cells and by inducing its differentiation in osteoprogenitor cells ${ }^{6}$.

Several techniques for reconstruction of the atrophic maxilla are described, all with the intent to promote a bone contribution to rehabilitation with dental implants. Thus, edentulous individuals can enjoy a very favorable prognosis, given the high predictability of success achieved in these treatment modalities.

The purpose of this study is to conduct a literature review of the various techniques for reconstructing the atrophic maxilla, discussing its advantages, indications and possible complications.

\section{LITERATURE REVIEW}

The vertical resorption of the maxilla is four times greater than that of the jaw. In the maxilla, the estimated annual average vertical bone resorption of $0.1 \mathrm{~mm}$

1. Post-Graduation Program, Dentistry, Faculty of Dentistry, Paulista State University- UNESP, Araçatuba, São Paulo State - SP, Brazil. 
after tooth loss. The atrophy is more pronounced in the first year after extraction and becomes less intense in the subsequent years ${ }^{7}$.

The horizontal resorption in both arches starts on the buccal surface and progresses in lingual and palatal direction. During the resorption process the lack of bone quantity (thickness and / or height) for the installation of dental implants in the anterior maxilla is common, whereas in the posterior one there is often sufficient bone thickness and insufficient height ${ }^{7}$.

A classification of the maxillary alveolar ridge was proposed based on cuts randomly performed on a sample of 300 dry skulls, serving to simplify the description of the alveolar ridge and to select the best surgical-prosthetic method $^{8}$ : Class I - serrated edge, maintaining the dimensions of the maxillary sinus by the presence of the dental element; Class II - immediately after tooth extraction, the socket is filled with reparative granulation tissue after recent dental extraction; Class III - rounded edge, with adequate and sufficient height and thickness for reconstruction with osseointegrated implant; class IV enough height, though with extensive horizontal bone resorption (knife blade-shaped edge). Need of increased bone thickness; Class V - inappropriate flat edge, bone resorption in height and thickness. Need of reconstruction in both dimensions; Class VI - depressed edge, extensive bone resorption and advanced pneumatization of the maxillary sinus.

According to Urist et al. ${ }^{6}$, reports on bone grafting start with Van Meeken, in 1682, reporting the successful transplant of a dog bone skull for a cranial defect in a man. Kuabara et al. ${ }^{2}$ revealed that the bone graft was completely dead several days after its transfer and that there was a restocking by living cells only through a gradual process of invasion of cells derived from the recipient bone.

Since then, many studies have been conducted with the intent of promoting better reconstruction of the atrophic maxilla. These grafts can be installed in the form of blocks (cortical or corticomedullary) or particulate. The grafts in blocks must be placed in the recipient area with screws and are positioned at the alveolar crest or in the vestibular region of the atrophic alveolar ridge (onlay graft), may also be brought under the floor of the maxillary sinus or the nasal passages (inlay graft) to simultaneously address the deficiencies in height and width7,9. The particulate medullary grafts can be placed under guided bone regeneration membranes, meshes of titanium or into bone cavities. In the initial phase of the integration of these grafts, remodeling with loss of bone volume ensues. The amount and speed of this resorption depends on various factors, such as the size of the graft, the type of bone graft, the receiving area and graft fixation in the zone ${ }^{7-10}$.

The selection of potential donors for bone reconstruction areas depends on the required volume of bone, the type of defect, type of bone graft (cortical, medullary or corticomedullary), of embryological origin and of operation morbidity. For small and medium bone defects intraoral donor areas are the chin, retromolar area and the maxillary tuberosity. For larger reconstructions external donor sites are the iliac bone, the cranial vault (parietal), tibia, fibula and ribs ${ }^{10}$.

\section{MAIN INTRAORAL DONOR AREAS FOR AUTOGENOUS GRAFTS}

\section{Maxillary tuberosity}

The tuber is basically an area of medullary bone. Depending on the anatomy, it offers small and medium quantities of bone, which may be removed bilaterally. It is used in grafts of dimples due to tooth loss in small fenestrations during preparation for placement of implants and grafts in maxillary sinus cavity. It is a filler bone, to be used in a particulate form. The anesthesia used is the posterior terminal infiltration (posterior superior alveolar nerve) and complementary on the edge and on the posterior palatine nerve. An incision is made with a total flap on the edge crest and on the vestibular. After the flap withdraw, the area becomes in evidence. At the end, bone regularization and suture are carried out (Figure 1: A, B and C).

Surgical risks and possible complications include: removal of too much bone, causing exposure of the maxillary sinus cavity and possible buccosinusal fistula; commitment of remaining teeth; mobility; necrosis; and even the need for extraction².

\section{Mental Region}

The Mental region is one of the best oral areas because it provides good quantity and quality of cortical and trabecular bone. The graft has the form of a semiarc, and can be used as a graft of types onlay (on the edge), inlay (within the cavity), sandwich (inside and outside of the remaining edge, usually in the maxillary sinus) or ground (to fill spaces between blocks or small defects and/or inside the maxillary sinus).

The technique consists of bilateral regional anesthesia of the inferior alveolar nerve, with possible supplementation by terminal infiltration at the bottom of the vestibule and lingual aspect of the incisors. The incision can be made on the crest and interdental papilla down to the periosteum. Then the flap is detached toward the base of the jaw. Once the bone tissue is exposed, the trephine drill is adapted to the handpiece, allowing removal of the graft in the shaped of pipe, resulting in cortical and medullary bone cylinders. Clinically, however, we note that in some situations one can only get the cortical part, with little medullary one. Another option, the stated choice, is the removal of cortical and medullary blocks by using 700 series low speed drills with cleft. In both situations, there is thorough irrigation with saline solution. The osteotomy is then completed by approximately 4 to $5 \mathrm{~mm}$ deep, depending on the mandibular thickness and defect area. The chisel or 

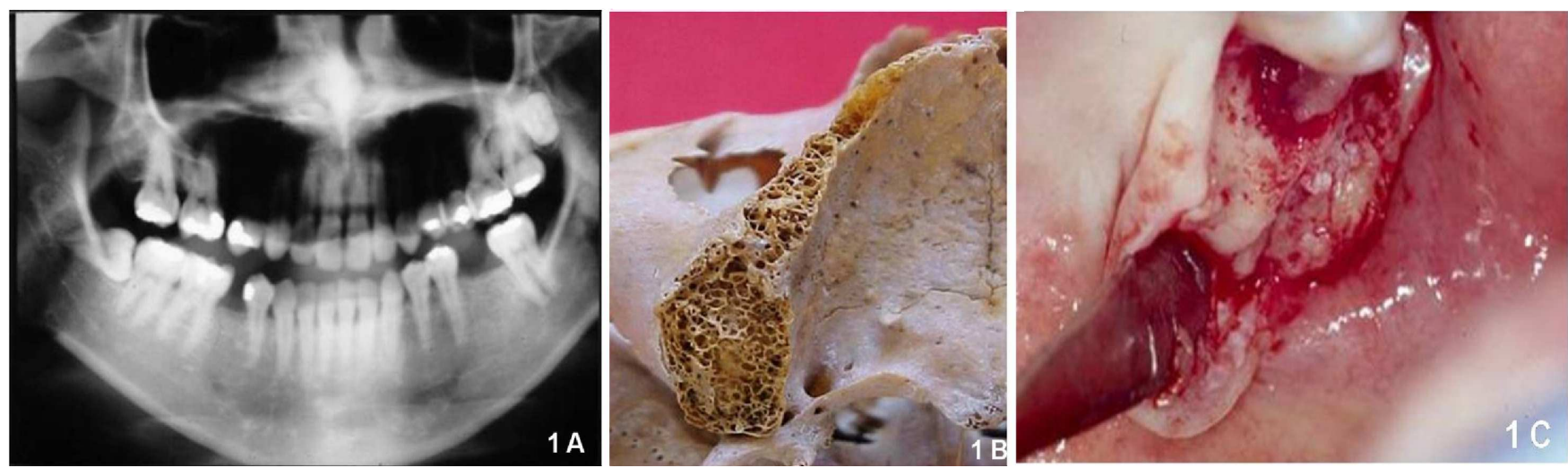

Figure 1 - A) radiographic appearance, showing the possibility of removing bone from the right maxillary tuberosity, B) in the dry skull, the presence of medullary bone C) tuberosity detached for graft removal.

levers (straight extractors) are placed in the slot created by the osteotomy and the block is separated, this way obtaining the cortical and medullary grafts (Figure 2: A, B, C and D).

The access and technique are simple, but require training and pre, peri and postoperative care. The area of bone repair should always be less than the amount of bone removed. The graft is remodeled according to the bone defect, and may be in the form of block and/or ground, in the anterior part (unit loss) or partial, or in a maxillary sinus. Complications related to this procedure are: hemorrhage, hematoma, edema, temporary or permanent lip and / or dental paresthesia, pulp devitalization and apicoectomy ${ }^{11}$.

\section{Retromalar}

In this area there a large amount of cortical bone, and little medullary one. Thus, the veneer-type graft (overlapping the remaining bone), onlay and/or inlay, is recommended. The thickness and size depend on the local anatomy, and access may be limited due to on the region being in the posterior part of the mouth. Sometimes, depending on the extent of bone loss, it is possible to remove the graft in the shape of " $\mathrm{L}$ ", enabling an increase in the height and width of the edge for small bone losses (one to three teeth) ${ }^{7}$.

The regional anesthesia used is the inferior alveolar nerve, with complementation through terminal infiltrative anesthesia in the anterior portion of the ascending ramus. The incision begins at the base of the ramus and follows the external oblique line to the region of the first molar. I can also be started in the ramus, continuing with an interpapillary incision to the region of the lower second premolar. The flap is total to the periosteum, exposing all the retromalar area and the external oblique line. With the 700 series drill at low speed or with minisaws, always with abundant saline irrigation, the area to be removed is delimited, the osteotomy is complete, and the bone block is removed with chisel and / or levers. It is difficult to delimit the entire area with osteotomy, because the lower area is difficult to access ${ }^{10}$.

For safety reasons, during this act it is advisable to support the lower border of the mandible and/or have the patient adopt almost occlusion to prevent injuries in the temporomandibular joint (TMJ) and even fractured mandible angle. The graft can be ground and / or used in block form. When the graft is block, it should be refurbished, fixed and optimally adapted to the bone defect. The bone of the retromolar area is of cortical type, and from the standpoint of access and postoperatively, this operation is similar to the removal of included third molars (Figure 3: A, $B, C$ and $D$ ).

The operative risks and possible complications in this area are: sectioning the neurovascular bundle of the
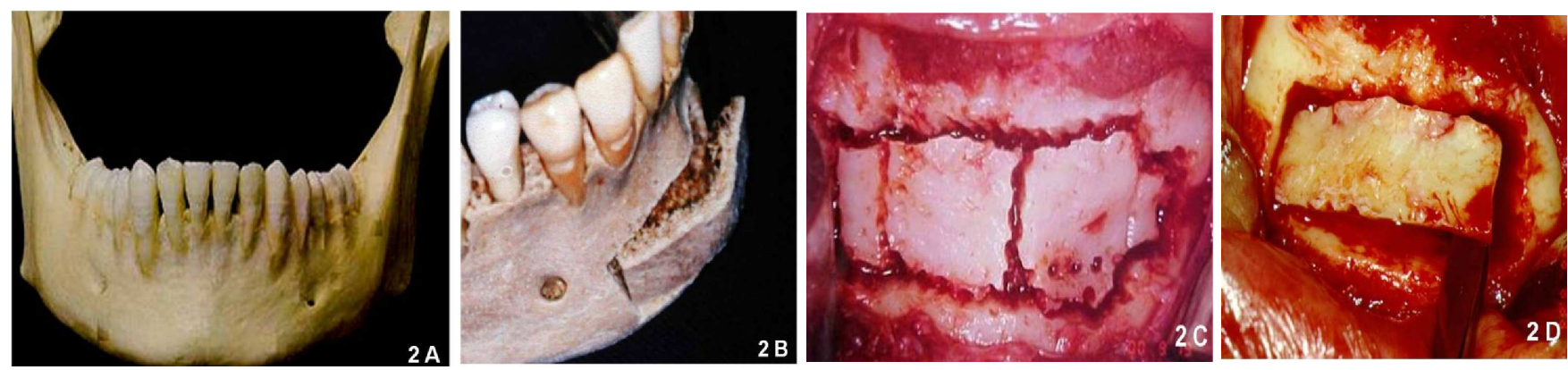

Figure 2 - A) anatomy of the mental region, B) osteotomy in dry skull, showing the proportion of cortical / medullary bone tissue, C and D) removal of bone blocks, alone or in parts. 
inferior alveolar, which can cause temporary or permanent paresthesia, hemorrhage and hematoma; injure or even section of the lingual nerve during tissue retraction, and mandibular fracture by the improper use of force during the removal of the graft or wrong surgical technique ${ }^{11}$.

\section{EXTRAORAL DONOR SITES FOR AUTOGENOUS GRAFTING}

\section{Iliac crest}

The iliac crest graft provides medullary and cortico-medullary bone in large quantities, enough for large maxillary reconstructions in thickness, height and bilateral elevation of the maxillary sinus floor. However, it has great postoperative morbidity, leaving the patient with a temporary difficulty in walking, which can be avoided by minimum dissection of the gluteus medius and maximum muscles' insertions. Due to its endochondral origin, this type of bone graft is resorbed more rapidly than the intramembranous grafts. In these cases, the maxillofacial team works closely with the orthopedic team, which is responsible for removal of the iliac crest bone graft $10,12,13$.

The surgical intervention should be performed in a hospital under general anesthesia. The elected removal area is the anterior superior iliac crest. The incision is made on plans to access the bone crest. The removal of the graft is performed using cylindrical saws or drills at low speed and chisels, with copious saline irrigation. The graft may be enclosed in the donor area with prefabricated U-shaped trays corresponding to the atrophic maxilla and mandible, in bicortical blocks (rare), cortical and medullary, or only medullary. The graft is carved and remodeled to better fit and fixation on the recipient area. The iliac offers a large amount of bone with predominance of marrow, and sometimes has texture comparable to the maxillary tuberosity bone. The area is then cleansed and drained (Figure 4: A, B, C and D).

Postoperative complications are due to carelessness and lack of skill of the surgeon, the extent of removal and sometimes the very anatomical structure of the patient. Generally, the complications are related to the amount of bone removed, and internal bleeding being may occur, with extensive areas of hematoma and edema, pain, penetration of abdomen and viscera injuries area, and rupture of the lateral femoral cutaneous nerve, which causes partial or permanent paresthesia of the lateral portion of the thigh and difficulty in walking ${ }^{12,13}$.

\section{Cranial vault}

The bone graft taken from the cranial vault provides large amount of cortical bone and small amount of medullary bone. By having intramembranous origin, it displays lower rates of resorption due to embryological resemblance to the jaw. The operation for removal of this type of graft requires good training of the surgeon and has a low rate of complications. The morbidity of the procedure is much lower when compared with the operation of the iliac crest. The bone is removed by the neurosurgery team, from outer cortex of the diploe at the parietal eminence between the lambdoid and the sagittal sutures, where the bone is somewhat thicker ${ }^{10,13}$.

Anesthesia is usually in a hospital setting, the trichotomy being indispensable. A good antisepsis with povidone is performed. The incision is total down to the periosteum or pericranium, the scalp being detached and the bone exposed. The osteotomy is performed under copious irrigation with saline, using 700 series drills at low speed, saw-type drills and chisels. An important detail: the depth limit of osteotomy is determined when the bone tissue starts to bleed, which indicates that the drill has reached the medullary part. The graft can be designed and sculptured in the shape of " $U$ " or strips of blocks, and then restored, adapted and determined according to the bone defect ${ }^{10}$.
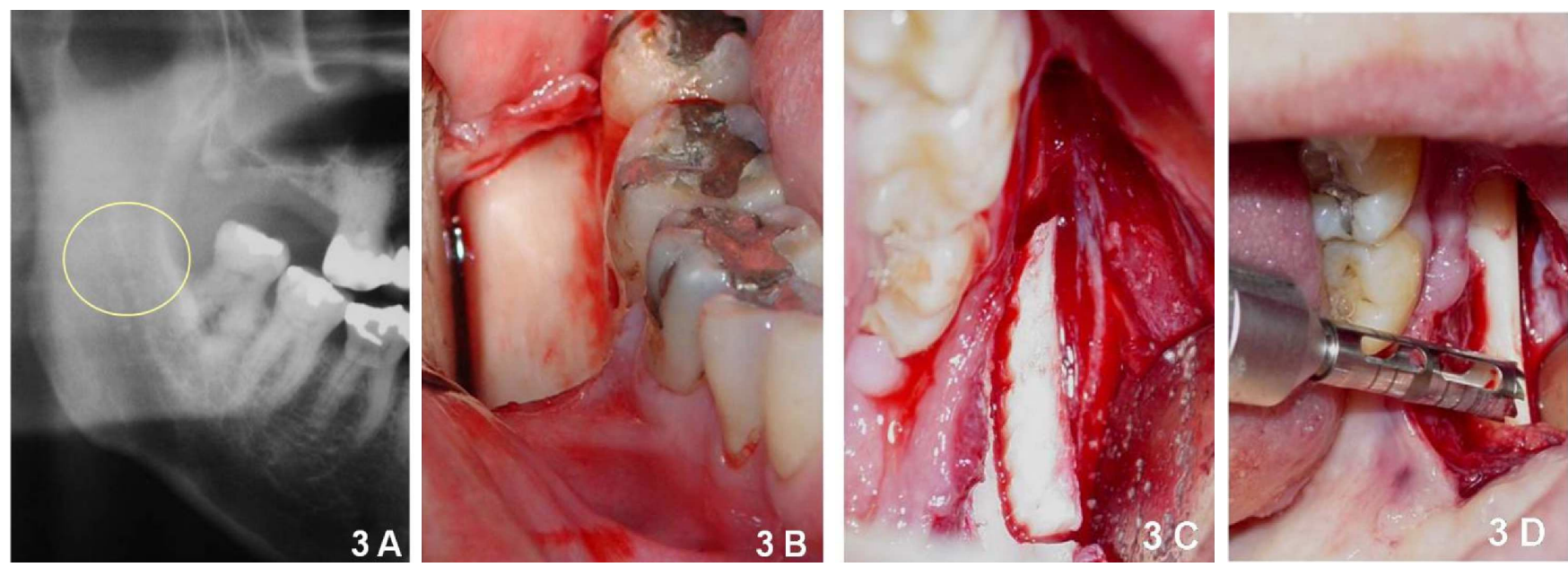

Figure 3 - A) radiographic image of retro-molar region to be the donor area of the graft, B) after incision on the external oblique line, detachment and design of the bone block (C) or removal with trephine (D). 

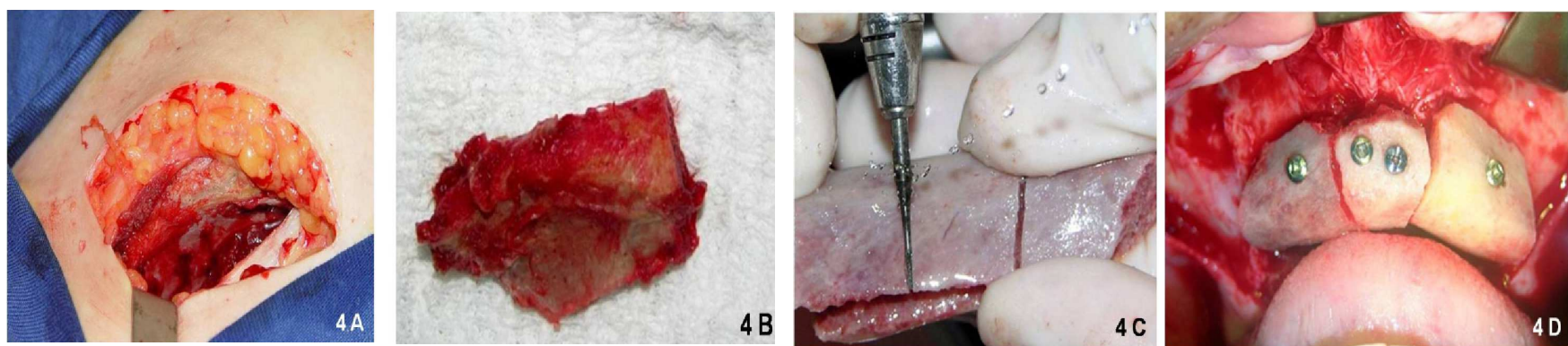

Figure 4 - A) access in the iliac crest region, B) bone block from the iliac for reconstruction of atrophic maxilla C) preparation of collected graft for fixation in the recipient bed, D) graft fixed to the jaw with titanium screws.

Some medullary bone is achieved adhered to the outside cortical, and large amounts of bone can be removed. The suture should be removed seven to 15 days (Figure 5: A, B and C) thereafter. The risks and possible complications are quite low and there are few reports of complications in the literature. It is worth noting, though that a small, controllable bleeding can occur with the section of the parietal branch of the superficial temporal artery. A worse scenario would be the penetration of cranial cavity during removal of the graft, leading to irreparable damage. There being surgical care and technical preparation, the cranial vault becomes an area of and easy access to large amount of cortical bone. The biggest caveat to the indication of this technique is related to its acceptance by the patient, and not to its surgical difficulty ${ }^{13}$

\section{Homologous Graft}

Nowadays, with the advent of guided bone regeneration, studies show that large reconstructions in the very near future may be performed with bone substitutes. It is known that autogenous bone will always be the gold standard for grafting. However, in view of the surgical morbidity and some inherent technical drawbacks, the use of allografts alone or associated with to xenografts will be more and more indicated.

The homologous bone may be frozen, dried, demineralized or not, and also lyophilized. By lyophilization it is understood the removal of moisture from the previously degreased bone, allowing its storage for long periods ${ }^{14}$. Currently, the most used homogenous bone is the dry frozen bone. It is readily available in large quantities, but revascularization takes longer compared with the autogenous bone and it has no osteoinductive potential ${ }^{15}$.

An alternative homologous bone is the fresh frozen bone. It is aseptically collected from living donors or cadavers, and then frozen. There is no additional preparation, and osteoinductive proteins are preserved. The demineralization process is used to expose the collagen of the graft organic matrix, and thus the BMP. The objective is to increase the osteoinductive potential of the graft $^{16}$.

\section{DISCUSSION}

In the attempt to compare the clinical outcomes involved with the use of autogenous bone grafts from intraoral donor sites for reconstruction of the atrophic maxilla, the literature is quite extensive. However, there are no clinically significant differences between them. Raghorbar et al. ${ }^{11}$ compared the grafts obtained from the mental area, retromolar region and the maxillary tuberosity for the correction of small bone defects and subsequent placement of dental implants. The results were satisfactory in all cases, with no great differences between them.
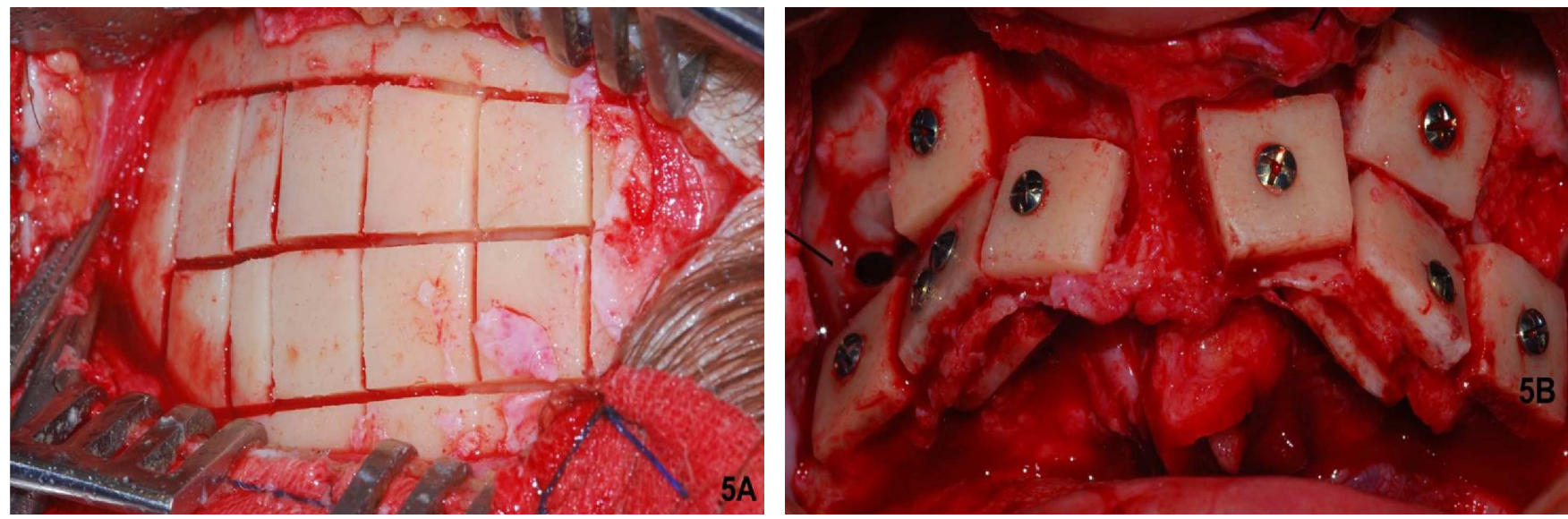

Figure 5 - A) accessed donor area (cranial vault), B) grafts fixed in the jaw with titanium screws. 
Misch ${ }^{17}$, on his turn, reports some advantages in obtaining teh graft from the mandible branch over the mental area, mainly due to postoperative complaints and complications. However, he points out the disadvantages of difficult access and the possibility of injuring the neurovascular bundle of the inferior alveolar. One must admit that the technique for obtaining intraoral grafts is much related to the skill of the surgeon, and especially to the characteristics of the graft that the case demands. Complications and surgical risks are thus minimized.

The ease of obtaining the graft and of accessing the maxillary tuberosity region is greater than it is in other intraoral areas. The bone tissue is characteristically medullary (spongy bone), of low volume and bone density, being more suitable for filling small bone defects ${ }^{2}$. It should be borne in mind that the X-ray analysis of the removed portion is mandatory in view of the high incidence of cellular extensions of the maxillary antrum, which could cause buccosinusal communication during grafting. Therefore, if the region of the maxillary tuberosity radiographically presents a greater proximity to the maxillary sinus floor, removal of bone tissue is contraindicated ${ }^{2,11}$.

In major reconstructions, whereby a quite considerable amount of bone is required, removal of grafts from extraoral areas is indicated. Initially, in all cases one should perform preoperative clinical and radiographic studies to determine the size of the bone defect in the maxilla and the amount of bone needed for reconstruction ${ }^{11}$. There are also reports in the literature of computed tomography to better 3D studying and more accurate planning ${ }^{18,19}$.

The donor sites used in most cases of large bone defects are the iliac crest and the cranial vault, both of which promoting adequate amount of both cortical and medullary bone. The iliac crest is less recommended as donor site due to the greater morbidity associated to changes in motor function and the patient's need to remain hospitalized ${ }^{10,12,20}$.

Harbon et al. observed low morbidity in removing iliac bone graft and stated that it is one of the best donor areas for craniofacial reconstruction ${ }^{21}$. However, they emphasized its disadvantage in relation to the level of bone resorption. In contrast, Dice and Izquierdo reported that there are advantages in the use of grafts of membranous origin (vault and jaw) over the ones of endochondral origin (ilium, tibia and rib) when considering bone resorption ${ }^{22}$. This difference is probably due to the more cortical characteristic of the bone of membranous origin. Regarding this controversy, widely discussed by the literature authors, the ones of this work, relying on clinical experience, agree that the features in regards to the type of ossification do not influence the type of bone graft repair. For the bone, after reaching the embryonic ossification process, is "bone tissue", with its sui generis characteristics, be it more cortical or more medullary. This is perhaps most associated with the rate of resorption of the different donor sites.

The quest for replacement by allogenic bone autografts has been increasingly growing, especially in reconstructions requiring a second surgical access, with the intent of reducing surgical morbidity ${ }^{5}$. However, there is still no concrete biological foundations for its use in isolation, especially in the reconstruction of atrophic maxilla. The literature is unanimous on the concept of its association with autogenous gafts, or even in the isolated filling of small bone defects $5,7-9,17$.

Thus, in cases of severe bone resorption or even bone defects of various causes, there are surgical resources that enable the improvement of local conditions for placement of dental implants in a more favorable position for prosthetic rehabilitation.

\section{FINAL CONSIDERATIONS}

Autogenous bone grafts remain in most cases the best method for repair of alveolar atrophy and bone defects. For the major reconstruction of atrophic maxilla, grafts from the cranial vault and iliac crest should be indicated. Medium and small bone defects should be treated with intraoral grafts, with good predictability of success. The donor area to be chosen is associated with the experience and skill of the surgeon and the characteristics of the region to be rebuilt.

\title{
R E S U M O
}

\begin{abstract}
Para a reabilitação bucal com as próteses implantossuportadas é necessário a realização de procedimentos para criar o volume ósseo necessário para a instalação dos implantes. Com isso, os enxertos ósseos provenientes de áreas doadoras intrabucais ou extrabucais, representam uma possibilidade bastante favorável. O presente trabalho objetivou realizar uma revisão da literatura em que procurou discutir parâmetros para as indicações, as vantagens e complicações para as técnicas dos enxertos ósseos autógenos.
\end{abstract}

Descritores: Maxila. Transplantes. Transplante ósseo. Próteses e implantes. Reabilitação bucal.

\section{REFERENCES}

1. Jung YS. Kim HJ. Choi SW, Kang JW, Cha IH. Regional thickness of parietal bone in Korean adults. Int J Oral Maxillofac Surg. 2003;32(6):638-41.
2. Kuabara MR, Vasconcelos LW, Carvalho PSP. Técnicas cirúrgicas para obtenção de enxerto ósseo autógeno. Rev Fac Odontol Lins. 2000;12(1/2):44-51.

3. Ahlmann E, Patzakis M, Roidis N, Shepherd L, Holtom P. Comparison of anterior and posterior iliac crest bone grafts in terms of harvest- 
site morbidity and functional outcomes. J Bone Joint Surg Am 2002;84-A(5):716-20.

4. Boyne PJ. The use of marrow-cancellous grafts in the regeneration of mandibular bone. Trans Int Conf Oral Surg. 1973;4:58-63.

5. Fugazzotto PA. Report of 302 consecutive ridge augmentation procedures: technical considerations and clinical results. Int J Oral Maxillofac Implants. 1998;13(3):358-68.

6. Urist MR, Mikulski A, Boyd SD. A chemosterilized antigen-extracted autodigested alloimplant for bone banks. Arch Surg. 1975;110(4):416-28.

7. Magini RS. Enxertos ósseos no seio maxilar. Estética e função. São Paulo: Santos; 2006

8. Cawood II, Howell RA. A classification of the edentulous jaws. Int J Oral Maxillofac Surg. 1988; 17(3):232-6.

9. Nary Filho H, Marques-Padovan LE. Fixação zigomática. São Paulo: Santos; 2008

10. Salim RA, Souza-Silva GH, Marzola C. Reconstrução de maxila atrófica com enxerto de crista do osso ilíaco - Revista da literatura e apresentação de caso clínico-cirúrgico. Rev Odontol. 2007:10(1):871-86.

11. Raghoebar GM, Timmenga NM, Reintsema $H$, Stegenga B, Vissink A. Maxillary bone grafting form insertion of endosseous implants: results after 12-124 months. Clin Oral Implants Res. 2001;12(3):27986.

12. Sjöström M, Sennerby L, Nilson $H$, Lundgren $S$. Reconstruction of the atrophic edentulous maxilla with free iliac crest grafts and implants: a 3-year report of a prsopective clinical study. Clin Implant Dent Relat Res. 2007;9(1):46-59.

13. Sbordone L, Toti $P$, Menchini-Fabris GB, Sbordone C, Piombino P, Guidetti F. Volume changes of autogenous bone grafts alveolar ridge augmentation of atrophic maxillae and mandibles. Int J Ora Maxillofac Surg. 2009;38(10):1059-65.

14. Lane SW, Guggenheim B, Egyedi P. Comparison of homogenous freeze-dried and fresh autogenous bone grafts in the monkey mandible. J Oral Surg. 1972;30(9):649-55.

15. Mulliken JB, Kaban LB, Glowacki J. Induced osteogenesis-the biological principle and clinical applications. J Surg Res. 1984;37(6):487-96.
16. Pogrel MA. The lower border rib graft for mandibular atrophy. J Oral Maxillofac Surg. 1988;46(2):95-9.

17. Misch C. Implantes dentários contemporâneos. $2^{a}$ ed. São Paulo: Santos; 2000.

18. Joahansson B, Grepe A, Wannfors K, Hirsch JM. A clinical study of changes in the volume of bone grafts in the atrophic maxilla. Dentomaxillofac Radiol. 2001;30(3):157-61.

19. Salvato G, Angilardi E. Calvarial bone grafts in severe maxillary atrophy: preprosthetic surgery with sedation. Implant Dent. 2007;16(4):356-61

20. Schwartz-Arad D, Levin L. Multitier technique for bone augmentation using intraoral autogenous bone blocks. Implant Dent. 2007;16(1):5-12.

21. Harbon S, Chartouni M, Ricbourg B. Morbidity of iliac bone grafts. A study apropos of 100 consecutive cases. Ann Chir Plast Esthet. 1991;36(1):45-50.

22. Dado DV, Izquierdo R. Absorption of onlay bone grafts in immature rabbits: membranous versus enchondral bone and bone struts versus paste. Ann Plast Surg. 1989;3(1):39-48.

Received on 20/08/2012

Accepted for publication 30/09/2012

Conflict of interest: none.

Source of funding: none.

\section{How to cite this article:}

Faverani LP, Ramalho-Ferreira G, Santos PH, Rocha EP, Garcia Júnior IR, Pastori CM, Assunção WG. Surgical techniques for maxillart bone grafting - literature review. Rev Col Bras Cir. [periódico na Internet] 2014;41(1). Disponível em URL: http://www.scielo.br/rcbc

\section{Address for correspondence:}

Leonardo Perez Faverani

E-mail: leobucomaxilo@gmail.com 